\title{
Finite Element Method Study on Stress State in Soil Induced by Agricultural Traffic
}

\author{
Adrian MOLNAR-IRIMIE* \\ Faculty of Agriculture, University of Agricultural Sciences and Veterinary Medicine Cluj-Napoca, \\ Romania; \\ * corresponding author: adimolus@yahoo.com
}

Bulletin UASVM series Agriculture 73(2)/2016

Print ISSN 1843-5246; Electronic ISSN 1843-5386

DOI 10.15835/buasvmcn-agr: 12415

\begin{abstract}
In general, when a tyre is running on a deformable soil, the soil compaction will occur not only on surface layers, but also on soil profile, in deeper layers. This leads to a series of negative effects not only on physical and mechanical properties of soil, but also influences the crops growth and the crop yield. For these reasons, currently are needed solutions to reduce soil compaction, caused mainly by agricultural implements passing on the soil surface in order to aply the specific crop production technologies. From our simulation we can draw the following conclusions: the soil stresses decreased with depth; the soil displacements magnitude increased with soil water content due to lower friction forces between soil particles (water acts like a lubricant between soil particles); decreasing rate for soil displacement is influenced by load magnitude and tyre inflation pressure; the soil particles moved in vertical plain from the top to the bottom, but also in horizontal direction, from the center to the edge in cross section and in longitudinal direction; the dimensions of the geometric shape of the mentioned soil volume is influenced by load and tyre inflation pressure. In this paper the agricultural traffic and its influence on stress state in soil, it was used a software application based on Finite Element Method, that has been proved to be a useful tool for soil compaction assessment in order to find the right decisions for a proper field traffic management.
\end{abstract}

Keywords: agricultural traffic, Finite Element Method, soil compaction, soil induced stresses.

\section{INTRODUCTION}

Generally soil compaction caused by agricultural traffic, has the effect of damaging the surface layers, surface soil structure and in depth, modifying the pore size distribution, pore continuity and permeability for water and air (Ranta et al., 2013; Ranta et al., 208). These may have negative effects on soil biological activity, on the physical and chemical properties, on production (Schjønning et al., 2004) and on energy consumption during tillage (Rusu, 2013; Soane and Van Ouwerkerk, 1994; Stănilă. 2014a; Stănilă. 2014b; Van den Akker and Arvidsson, 2000).

In order to make detailed studies on the factors influencing soil compaction there were developed analytical and numerical techniques (Drocaş, 1993) that can be used to predict soil compaction in several conditions, that can be grouped in: soil status, soil loading regime, soil behaviour under external loads.

In this paper is used a numerical tehnique called Finite Element Method (FEM) and a FEM based software (PLAXIS) that has been made as a finite element code for 2D plane strain and axisymmetric modelling of soil and rock behaviour.

\section{MATERIALS AND METHODS}

A structural analysis in PLAXIS software involves the three main stages: designing the model computation initial hypotheses, setting the computing system, stresses and displacements computing, results analysis.

The first stage has following steps:

- geometric modeling of soil: soil is considered a cylindrical profile so that the soil-loading case show symmetry in terms of geometry and loading (plain model and axially-symmetric);

- imposition of boundary conditions, i.e. 


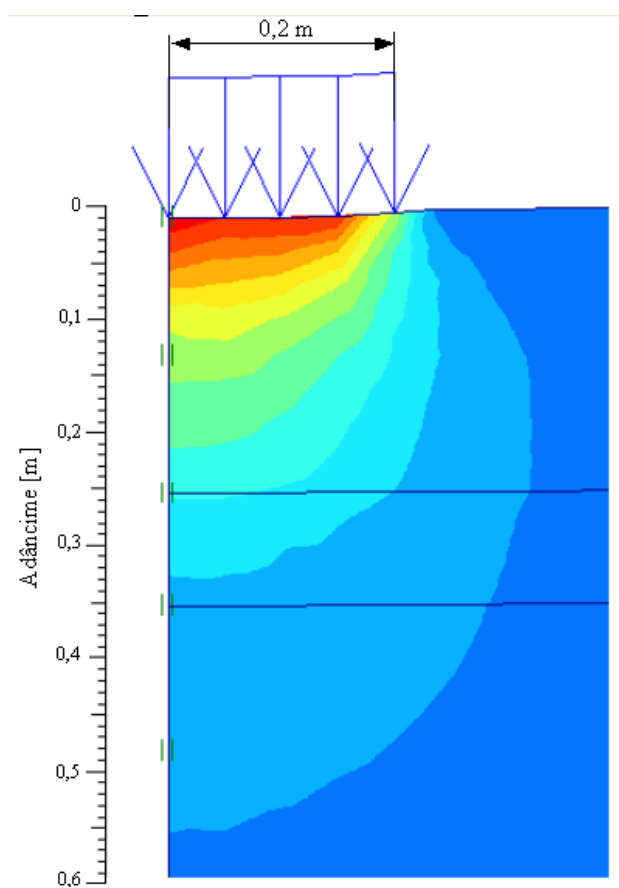

a)

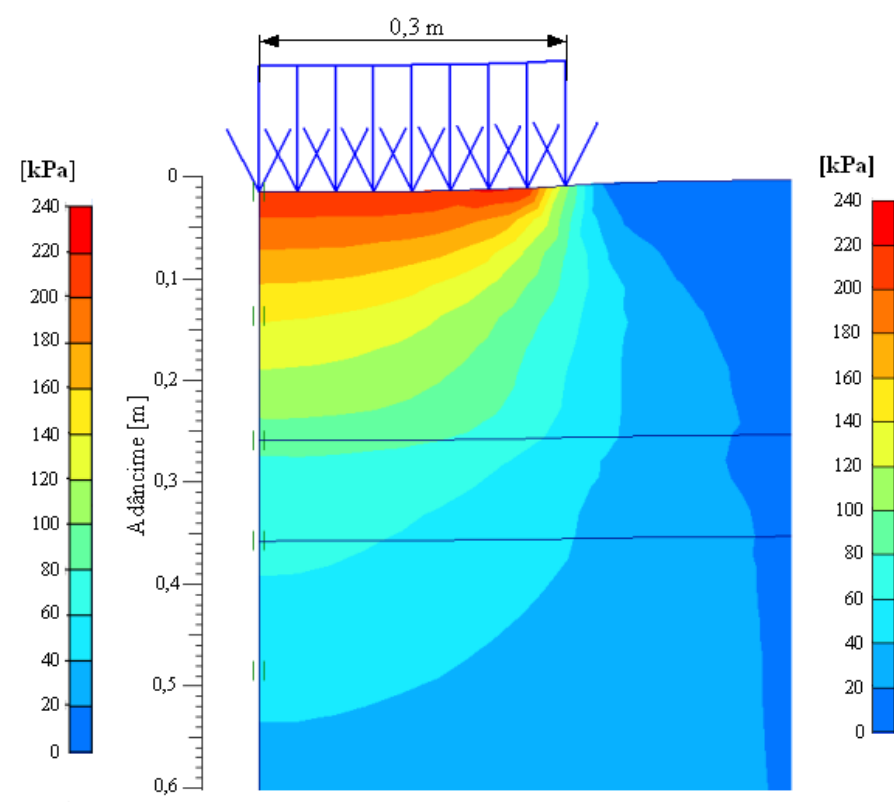

b)

Fig.1. Vertical stresses variation on soil profile depending on loading regime

a) wheel load $32000 \mathrm{~N}$, air pressure in tyre $210 \mathrm{kPa}$;

b) wheel load $71400 \mathrm{~N}$, air pressure in tyre $210 \mathrm{kPa}$

specifying the points for support and type of support, and what kind of loads acts on the considered geometry (e.g. load evenly distributed);

- setting the soil general characteristics: material parameters, material model (MohrCoulomb and Soft-Soil), soil type in relation to water (drained, undrained);

- mesh the geometric model: dividing the finite element geometry (triangular elements).

- The second stage has following steps:

- setting the computing case (plastic, consolidation, dynamic loading);

- setting the number of calculation steps;

- specifying multiplication factors of loading. Once these intermediate steps are defined, the stresses and displacements are computed.

The third stage is described as follows:

- to facilitate the processing of results, the program has a module which can be used to draw graphs of interdependence between different defined parameters, displays the actual stress distribution, the main points with plastic deformation, total and specific displacements in all points of the computed structure.

\section{RESULTS AND DISCUSSION}

Regarding the stress values at surface level contact between the tyre and the soil, it was showed that up to a depth of between $0.13 \mathrm{~m}$ and $0.18 \mathrm{~m}$, the stresses does not vary greatly, even if the applied load situations it is less than 50\%-60\% of the maximum value. This is mainly due to the fact that the size of the contact surface calculated depends mainly on tyre air pressure and load value due to the simplifying assumptions and limitations of the computer software.

There was thus concluded that stresses values from surface layer of soil mainly depends on the value of air pressure in the tyre, conclusion that is confirmed both by the results of theoretical and experimental research conducted by the author and the results obtained by other researchers in the field.

There are, however situations where a certain combination of the value of air pressure in the tyre and loading stresses in soil are greater when the air pressure in the tyre is higher, even if the wheel load is lower by $5 \%$ of the value taken as a reference. This applies to a maximum depth of 0.2-0.3 m, depending on the value of wheel load, observing that the stresses at this depth value 


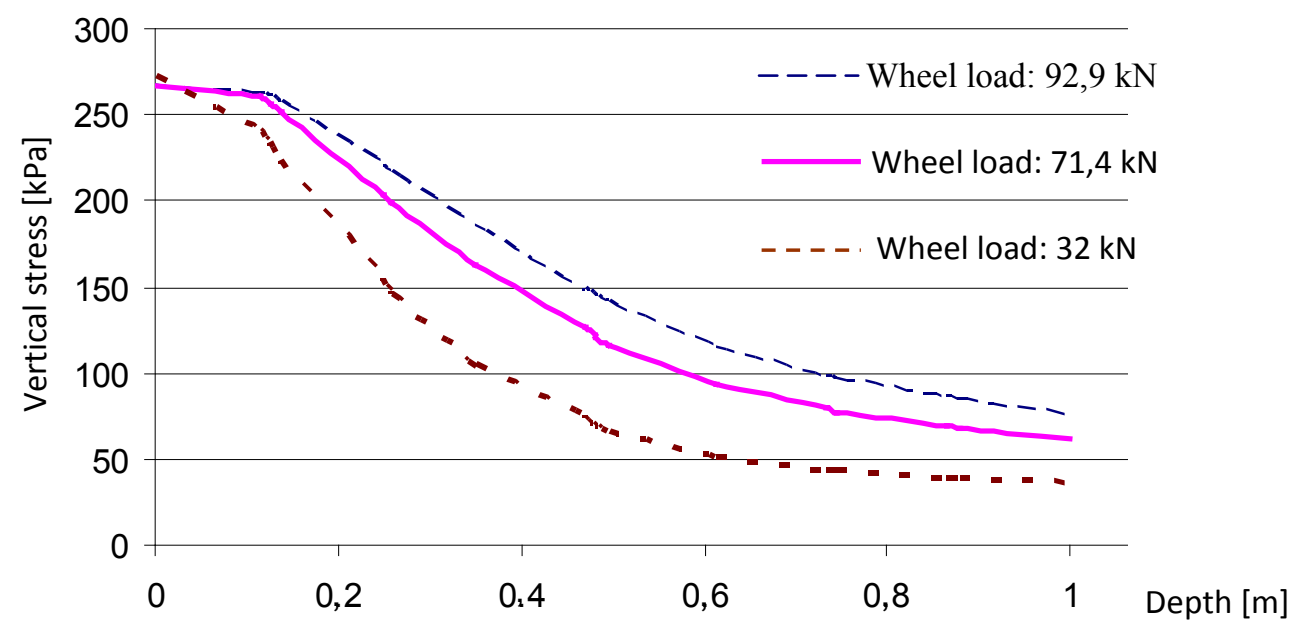

Fig.2. Vertical stresses variation on soil profile (in the centre of the loaded surface) depending on wheel load (air pressure in tyre $210 \mathrm{kPa}$ )

depends mainly on the amount of load on the wheel, even if surface contact is higher.

Hence it can be concluded that to reduce soil compaction in depth is better, for practical reasons, to reduce the wheel load, than to use tyres with higher contact surface with the soil, which allow a higher a wheel load

From the computed stresses results that initial soil compaction is particularly important in the tensions induced in the subsoil. Thus, in these situations (Fig. 1 and Fig. 2) it has been showed that because of a compact layer of soil to a depth of $25 \mathrm{~cm}$, the soil compaction occurs mainly up to this depth, the curves slope of vertical stresses having an inflection points at the mentioned depths.

In all cases in which it is considered that there is a layer of compacted soil at a certain depth, it has been found a sharp decrease of the value of the vertical stresses at higher depths than the depth of the layer in which it is situated. In practical terms this means that in situations where the soil profile meet soil layers average or very compacted, soil compaction will not expand in depth but will extend to the surface.

Another conclusion which follows from this is that when it is desired to measure the

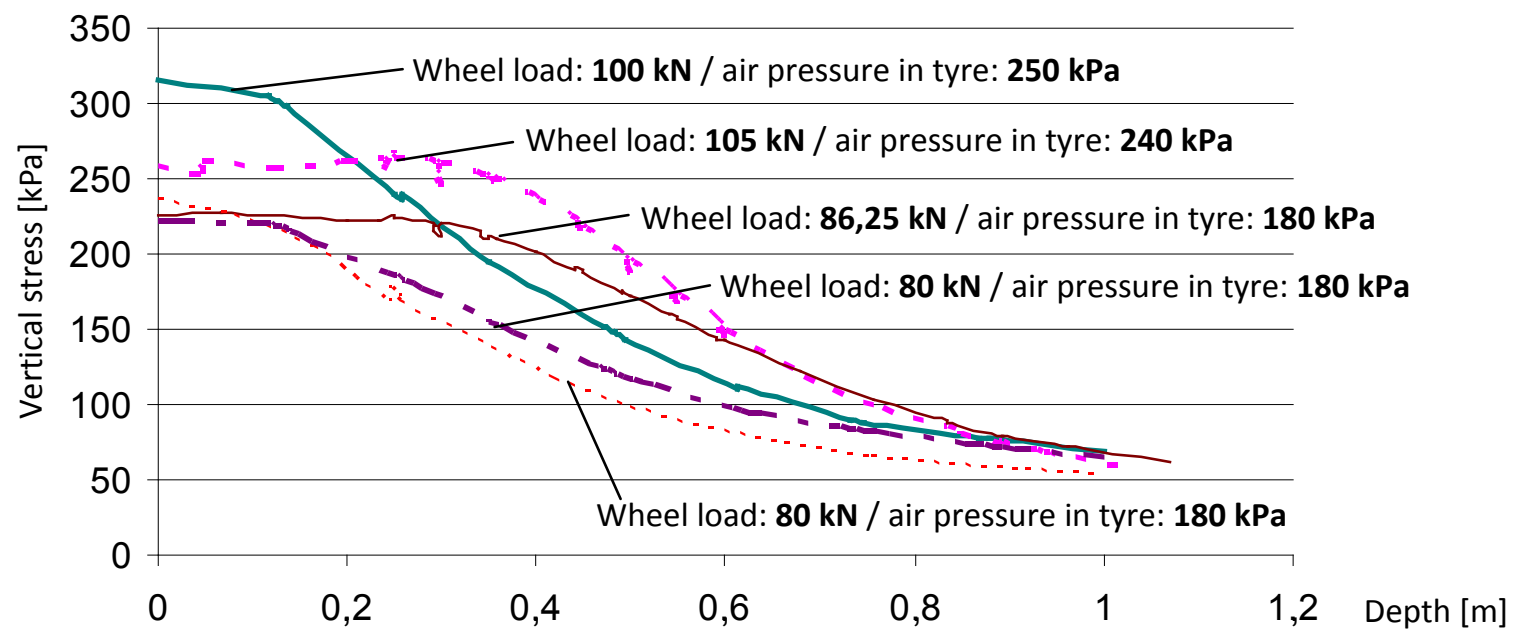

Fig.3. Vertical stresses variation on soil profile (in the centre of the loaded surface) depending on wheel load and air pressure in tyre 


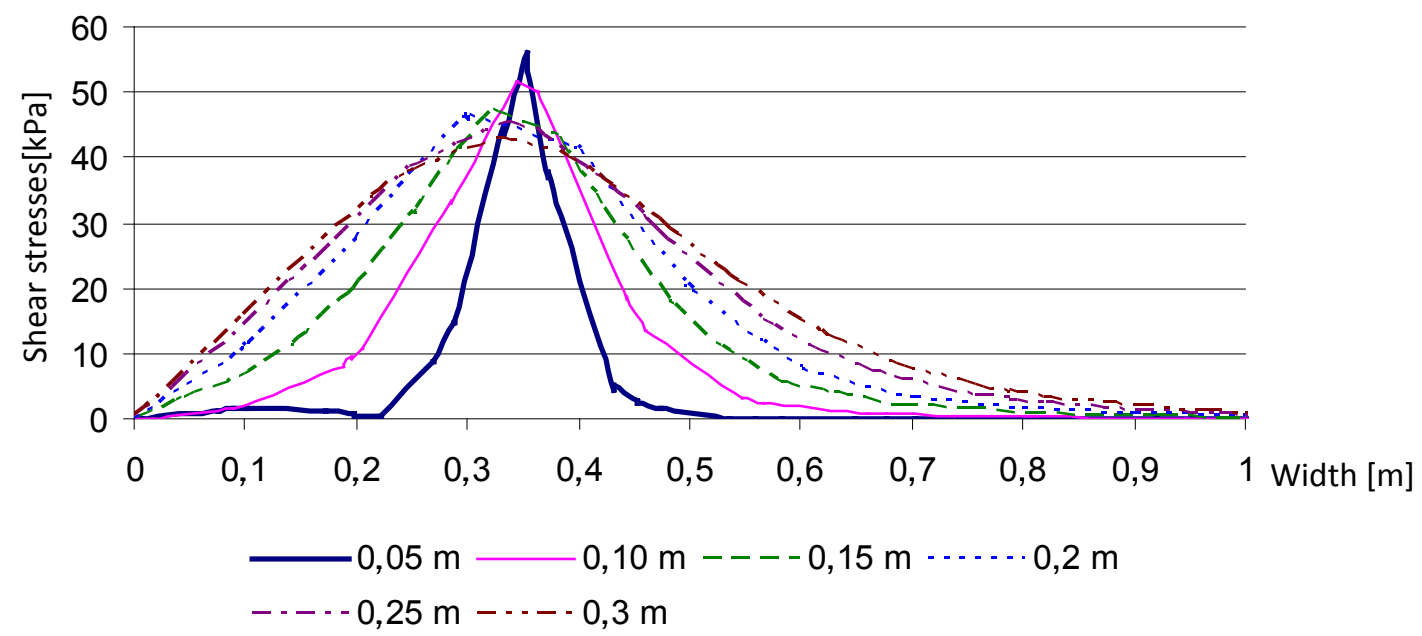

Fig.4. Computed shear stresses at several depths and on the width on the tyre contact surface

stresses in the soil it is not a good ideea to place the pressure transducers on the support that can not be deformed together with the ground in its neighborhood because, due to their rigidity, the measured stresses at the transducers will be at least $10-20 \%$ higher than real ones.

From this point of view the best situation is that the transducers are flexible as thin, large contact area with the ground and should be installed in the soil so that it can move with nearby soil particles.

To compare the influence of the loading regime for different settlement states of soil were considered three cases: compacted soil, soil with average compaction and loose soil. Also, for the last two cases it was considered that there is a layer of compacted soil at a depth of $0.25 \mathrm{~m}$ to 0.35 $\mathrm{m}$ and 0.3 to $0.35 \mathrm{~m}$, respectively. Thus it can be shown that in the case of loading the the tyre air pressure is $180 \mathrm{kPa}$ (Fig.3), the vertical stress at a depth of $0,1 \mathrm{~m}$ are greater for soils with larger deformations and with a low modulus of elasticity. In the same case, the smallest vertical tensions are obtained for soils that have a higher modulus.

Using the mentioned loading regimes it was computed shear stress distribution in the soil, both in depth and on the width of contact surface between tyre and soil. In all situations the

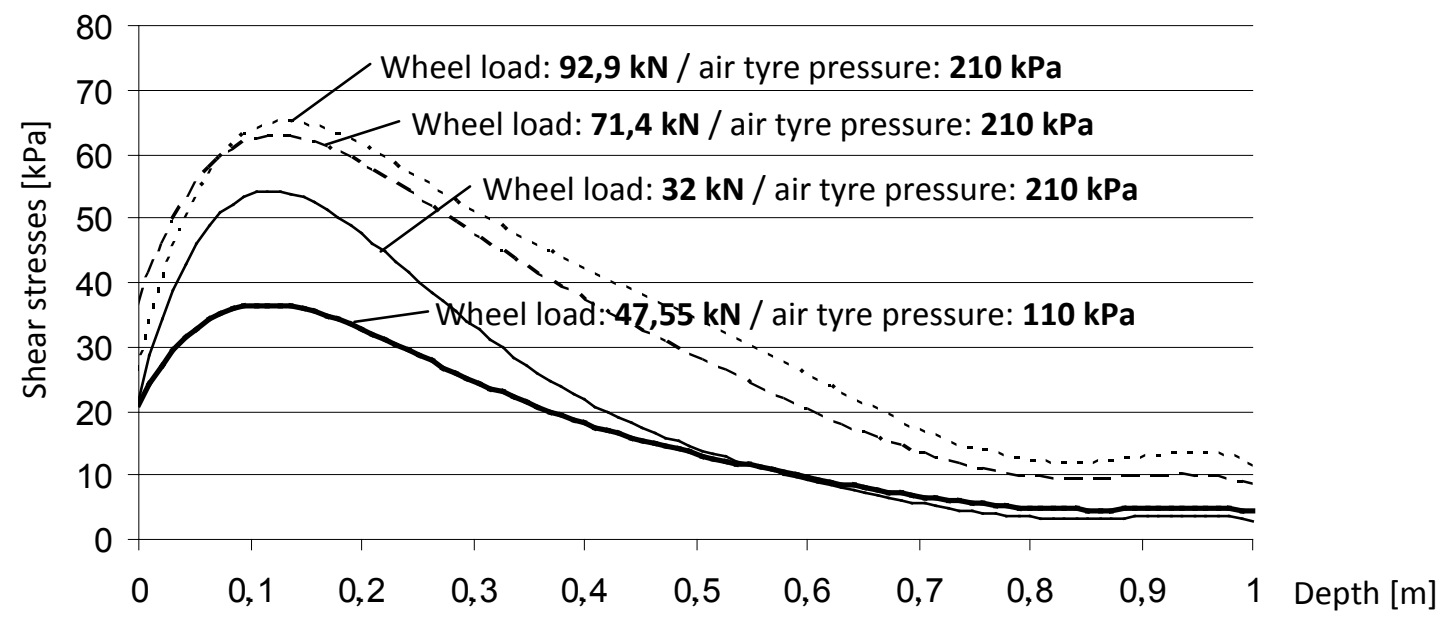

Fig. 5. Computed shear stresses on the soil profile 
maximum shear stresses are located at the edge of the transition area between the loaded soil surface and unloaded soil (Fig.4).

This aspect was studied and the distribution of stresses shear, especially in the area of the transition area where, for experimental researches, it has been observed the occurrence of fractures oriented in directions diverging from the position of the contact surface between the soil and the wheel.

Thus, in Fig.4 is showed that the maximum shear stresses are located at depths by $5 \mathrm{~cm}$ and $10 \mathrm{~cm}$, after which they decrease with increasing depth, with notable values to a depth not exceeding $0,7 \mathrm{~m}$.

On the soil profile (Fig.5) shear stresses are particularly dependent on tyre air pressure, wheel load being the second parameter that has influence on theyr distribution in soil. The slope of the shear stresses curves depends in particular on the mechanical properties of soil being higher for loose soils.

\section{CONCLUSIONS}

From this study the following conclusions can be drawn:

- due to the soil-tyre interaction the agricultural soil is subjected to stresses, leading to deformations caused by the lateral movement of soil particles in the vertical plain (on the direction of the external load) and in the horizontal plain;

- the soil-tyre interaction is changing the initial stress and strain state in the soil, being influenced by a number of parameters that take into account both the physical and mechanical properties of the soil and parameters related with external load (wheel load, size of the contact surface, air tyre pressure);

- in cross view, because of the particles movement, it's possible to see that the width of the soil volume influenced by the load is higher than the width of the contact area;

- in longitudinal view the length of the the soil volume influenced by the load it's higher than the length of the contact area;

- the shape of the soil volume influenced by the load is a frustum of a cone, with the low base in the contact area between soil and tyre and with high base at a certain depth, depending on the load magnitude;

- the dimensions of the geometric shape of the mentioned soil volume is influenced by load and tyre inflation pressure.

\section{REFERENCES}

1. Drocaş I (1993). Studiul tensiunilor ce apar în sol sub acțiunea brăzdarelor utilizând metoda elementului finit, Buletinul Universității de Ştiințe Agricole Cluj-Napoca, A-H, 47 (1): 137-143.

2. Ranta O, Drocaş I, Stănilă S, Molnar A, Muntean M, Marian $O$ (2013). Influence the Coulter Type on the Seed - Soil Contact in No-till Technology, Bulletin of USAVM 70(1):220-226.

3. Ranta O, Koller K, Ros V, Drocaş I, Marian O (2008). O. Study regarding the forces that occurs in a notill technology process in relation with geometrical parameters of the coulter discs, Bulletin UASVM, Agriculture 65(1): 200205.

4. Rusu $\mathrm{T}$ (2013). Water Conservation in Soil by Unconventional Soil Tillage Systems, ProEnvironment nr. 6 (2013): 115-120.

5. Soane BD, Van Ouwerkerk C (editors) (1994). Soil compaction in crop production, Elsevier Science B.V.

6. Schjønning P, Elmholt S, Christensen BT (editors) (2004). Managing soil quality: challenges in modern agriculture, CAB International.

7. Stănilă S (2014a). Development of an equipment for in field measuring of traction forces during soil tillage, Buletin USAMV seria Agricultura 71(2): 166-170.

8. Stănilă S (2014b). Aspects regarding on fuel consumption at tillage on slopes, Agricultura, agricultural practice and science journal, 1-2:80-85.

9. Van den Akker JJH, Arvidsson J (editors) (2000). Subsoil compaction. Distribution, processes and consequences, Catena Verlag. 